\title{
Effects of Different Leukocyte Subpopulations and Flow Conditions on Leukocyte Accumulation during Reperfusion
}

\author{
Annette Ploppa ${ }^{a} \quad$ Miriam Kampmann $^{a} \quad$ Tanja Johannes $^{b}$ Helene A. Haeberle ${ }^{a}$ \\ Boris Nohéa \\ ${ }^{a}$ Department of Anaesthesiology and Intensive Care Medicine, University Hospital, Eberhard-Karls University, \\ Tübingen, Germany; ${ }^{\text {b}}$ Department of Anesthesiology, Erasmus Medical Center, University Medical Center, \\ Rotterdam, The Netherlands
}

\section{Key Words}

Shear stress · Adhesion molecules • Reperfusion • Inflammatory response

\begin{abstract}
Background/Aims: The study examined the interdependent effects of shear stress and different leukocyte subpopulations on endothelial cell activation and cell interactions during low flow and reperfusion. Methods: Human umbilical venous endothelial cells were perfused with either neutrophils or monocytes at different shear stress (2-0.25 dyn/ $\mathrm{cm}^{2}$ ) and adhesion was quantified by microscopy. Effects of adherent neutrophils and monocytes on endothelial cell adhesion molecule expression were analyzed by flow cytometry after 4-hour static coincubation. After coincubation, the cocultures were reperfused with labeled neutrophils at $2 \mathrm{dyn} / \mathrm{cm}^{2}$ and their adhesion was quantified selectively. For the control, endothelium monocultures with and without lipopolysaccharide activation were used. Results: At 2 dyn/ $\mathrm{cm}^{2}$, adhesion did not exceed baseline levels on nonactivated endothelium. Decreasing shear stress to $0.25 \mathrm{dyn} / \mathrm{cm}^{2}$ largely increased the adhesion of both leukocyte subpopulations, similar to the effect of lipopolysaccharide at $2 \mathrm{dyn} /$ $\mathrm{cm}^{2}$. However, only adherent monocytes increased adhesion molecule expression, whereas neutrophils had no ef-
\end{abstract}

fect. As a functional consequence, adherent monocytes largely increased neutrophil adhesion during reperfusion, whereas adherent neutrophils did not. Conclusion:Compromised shear stress is an autonomous trigger of leukocyte adhesion even in the absence of additional activators. Exceeding this immediate effect, adherent monocytes induce further endothelial activation and enhance further neutrophil adhesion during reperfusion.

Copyright $\odot 2012$ S. Karger AG, Basel

\section{Introduction}

Compromised tissue perfusion and leukocyte-related tissue damage are central to the pathophysiology of organ dysfunction during ischemia/reperfusion (I/R), shock and systemic inflammation $[1,2]$. At normal blood flow, leukocyte adhesion depends on the inflammatory activation and upregulation of endothelial cell adhesion molecules such as endothelial (E)-selectin, intercellular adhesion molecule (ICAM)-1 and vascular cell adhesion molecule (VCAM)-1. Once expressed, these molecules bind to their leukocyte receptors and allow leukocytes to adhere to the endothelium against the opposing shear forces of blood flow [3-5]. While the inflammatory activation of adhesion molecules is one important trigger for adhe-

\section{KARGER \\ Fax +41613061234 \\ E-Mail karger@karger.ch}

www.karger.com (c) 2012 S. Karger AG, Basel

$1018-1172 / 12 / 0492-0169 \$ 38.00 / 0$

Accessible online at:

www.karger.com/jvr
PD Dr. Boris Nohé

Department of Anaesthesiology and Intensive Care Medicine

University Hospital, Eberhard-Karls University

Hoppe-Seyler-Strasse 3, DE-72076 Tübingen (Germany)

Tel. +4970712986622, E-Mail boris.nohe@med.uni-tuebingen.de 
sion, decreased shear stress may be another. Both in vitro and in vivo, decreasing shear stress increases adhesion in the presence $[4,6,7]$ and even in the absence of concurrent inflammatory activation [6,8-10]. Since leukocyte adhesion results in endothelial activation and further leukocyte-endothelial interactions [3, 11-13], adhesion at low shear stress may have a substantial influence on the inflammatory response. However, because low shear stress, low flow, hypoxia and inflammation are heavily interrelated in vivo, it has remained elusive so far whether low shear stress precedes leukocyte adhesion or whether leukocyte adhesion precedes malperfusion [3]. For similar reasons, it is still unknown if adhesion during low shear stress is only a limited phenomenon, restricted to the period of low blood flow, or if it acts as an initiator and propagator of subsequent inflammation and further hypoperfusion during reperfusion.

Apart from the complex interactions of shear stress, inflammation and adhesion, another important gap in knowledge is the interplay of different leukocyte subsets. As most studies on cellular interactions during shock and I/R focused on single adhesion triggers and single leukocyte subpopulations, their interplay is poorly understood. Although activated neutrophils are considered key effectors in reperfusion injury, studies from other fields of research provide evidence for a contributory role of monocytes; here adherent monocytes increased E-selectin expression and favored a subsequent accumulation of neutrophils [13-15]. However, definite conclusions on the relative contribution of both leukocyte subpopulations are prohibited by the lack of comparative studies and the confounding effects of traditional cell purification on leukocyte adhesion molecule expression. While some of these studies documented a considerable variation in unintended leukocyte activation [13], but others did not control for this confounder [14, 15], a controversy remains as to whether decreased shear stress alone represents an independent trigger for adhesion and subsequent inflammation [3].

Using varying levels of shear stress in a flow-chamber model with controlled leukocyte separation, we examined the interactions of neutrophils and monocytes with the endothelium to answer the following questions. First, does decreased shear stress induce leukocyte adhesion in the absence of additional activators? Second, does this adhesion induce endothelial activation? Third, what are the consequences of shear-stress-related cell interactions when flow is restored? And fourth, are there differences between neutrophils and monocytes with regard to the endothelial response to adhesion?

\section{Methods}

Endothelial Cell Culture and Leukocyte Separation

After obtaining approval from the local Ethics Committee (reference numbers 315/99 and 69/2003-A) and written informed consent, human umbilical venous endothelial cells (HUVEC) and citrated blood samples were taken from healthy pregnancies or female volunteers, with no coexisting cardiovascular risk factors or recent drug intake. HUVEC were prepared as previously described [16]. A purity and viability of $>90 \%$ was confirmed by staining for von Willebrand factor and Trypan blue (Sigma, St. Louis, Mo., USA). First-passaged HUVEC were plated at high density on rectangular coverslips precoated with collagen I (Falcon Biocoat ${ }^{\mathrm{TM}}$ BD-Labware, Bedford, Mass., USA) and used for the experiment within $24 \mathrm{~h}$ after reaching confluence. Functional quality of HUVEC was assessed by flow cytometric analysis of adhesion molecule expression on nonactivated and lipopolysaccharide-activated cell cultures (4 h, $100 \mathrm{ng} / \mathrm{ml}$ LPS from Escherichia coli, serotype 026:B64; Sigma). For staining, saturating amounts of fluorochrome-conjugated monoclonal antibodies $(\mathrm{mAb})$ against E-selectin (AC1.2, BD-Biosciences Pharmingen, San Jose, Calif., USA), ICAM-1 (H84H10, Immunotech, Marseille, France) and VCAM-1 (1.G1b1, Southern Biotechnologies, Birmingham, Ala., USA) were used.

Polymorphonuclear neutrophils (PMN) were isolated by density gradient centrifugation at $1,700 \mathrm{rpm}$ on a discontinuous Percoll gradient (Percoll $1.130 \mathrm{~g} / \mathrm{ml}$ Amersham Pharmacia Biotech, Uppsala, Sweden). The bottom layer was collected and contaminating erythrocytes were removed by hypotonic lysis in $10 \%$ $\mathrm{NH}_{4} \mathrm{Cl}$ (Sigma) on ice. After washing, the PMN pellet was restored in cold Medium 199 (Invitrogen Karlsruhe, Germany) to 5 $\times 10^{7}$ cells $/ \mathrm{ml}$ until use. Monocytes were isolated by density degree centrifugation and magnetic separation as previously described [16]. Following centrifugation at $440 \mathrm{~g}$ for $40 \mathrm{~min}$ over a discontinuous Ficoll gradient (Amersham Pharmacia Biotech), the mononuclear cell fraction was harvested from the interface between the Ficoll layer, and the plasma and contaminating erythrocytes were removed by hypotonic lysis in $10 \% \mathrm{NH}_{4} \mathrm{Cl}$ on ice. For magnetic separation, the mononuclear cell fraction was labeled with anti-CD33 mAb (AC104.3ES, Miltenyi Biotec Bergisch Gladbach, Germany) and placed on the prechilled magnetic separation column (VarioMACS ${ }^{\mathrm{TM}}$, AS, Miltenyi Biotec, Auburn, Calif., USA). After flushing out unlabeled cells with buffer, the column was taken out of the magnetic field and the CD33+ monocytes were collected from the effluent. After centrifugation, the monocytes were resuspended in cold Medium 199 to $1 \times 10^{7}$ cells/ml until use. The purity of both leukocyte subpopulations (>90\%) was confirmed by flow cytometric analysis of CD45 (J33, BD-Biosciences Pharmingen), CD15 (28, Southern Biotechnologies) and CD14 (Tuek4, Immunotech). A subset of PMN suspensions $(\mathrm{n}=3)$ from which monocytes had not been removed during cell separation was used in separate experiments to control for hidden effects of CD33-labeling.

To avoid unintended activation of leukocyte adhesion molecules during rewarming prior to the adhesion assay, we reconstituted the PMN and monocyte suspensions to $10^{6}$ cells $/ \mathrm{ml} \mathrm{just} \mathrm{be-}$ fore the adhesion assay in Medium 199 at room temperature. Final rewarming to $37^{\circ} \mathrm{C}$ was achieved in the flow channel of the heatable flow chamber. For quality control, expression of L-selectin and CD11b on isolated and stepwise rewarmed leukocytes was 
compared to the expression on leukocytes from freshly drawn whole blood. L-selectin and CD11b were stained with fluorochrome-conjugated mAb Leu-8 and CR3 (obtained from BD-Biosciences Pharmingen and Caltag, San Francisco, Calif., USA, respectively) and analyzed by flow cytometry.

\section{Adhesion Assay}

Leukocyte adhesion to HUVEC was examined in a temperature-controlled parallel-plate flow chamber (Kindler, Freiburg, Germany) with a laminar flow profile (Reynolds number $<1$ ) by phase-contrast microscopy $(\times 20$, DMIRB; Leica, Bensheim, Germany) as previously reported $[16,17]$. Using a syringe pump (PHD 2000; Harvard Apparatus, Natick, Mass., USA), PMN or monocyte suspensions $\left(10^{6} \mathrm{cells} / \mathrm{ml}\right)$ were perfused over either nonactivated or activated HUVEC (LPS $100 \mathrm{ng} / \mathrm{ml}, 4 \mathrm{~h}$ ) for $10 \mathrm{~min}$ at two different shear stress levels of 2 and $0.25 \mathrm{dyn} / \mathrm{cm}^{2}$. Given the constant viscosity of the perfusate ( 0.007 poise), changes in shear stress were elicited at a constant size of the flow channel $(1.25 \times$ $0.02 \mathrm{~cm}$ ) by different flow rates of 1.4 and $0.18 \mathrm{ml} / \mathrm{min}$, respectively.

Leukocyte adhesion was determined from digitized 10-second video recordings (camera AVT-BC 11/GR, Sony; modified by AVT Horn, Aalen, Germany) of 5 different fields of view at the end of each perfusion period using customized software for image recognition (CellTracker, C. Zanke, University of Tübingen, Germany). Leukocytes were defined as rolling when traveling below 40 $\mu \mathrm{m} / \mathrm{s}$ [4]. A leukocyte, moving less than 1 cell diameter in $10 \mathrm{~s}$ was defined as firmly adherent. To differentiate adhesion from passive sedimentation at $0.25 \mathrm{dyn} / \mathrm{cm}^{2}$ we exposed the adherent leukocytes stepwise to $32 \mathrm{dyn} / \mathrm{cm}^{2}$ after the end of the adhesion experiment, and measured cell detachment. Under this exposure $>70 \%$ of the adherent PMN remained bound.

\section{Effects of PMN and Monocyte Adhesion on Endothelial Cell}

\section{Adhesion Molecule Expression}

HUVEC were incubated with PMN or monocytes for $4 \mathrm{~h}$. For this purpose, static coincubation was preferred over perfusion at $0.25 \mathrm{dyn} / \mathrm{cm}^{2}$ to avoid potential damage to the endothelial monolayer during removal from the flow chamber. As determined from preliminary experiments, static coincubation with $\mathrm{PMN}$ or monocytes at $2.5 \times 10^{5}$ cells $/ \mathrm{ml}$ resulted in a similar degree of adhesion than previously observed for monocytes at $0.25 \mathrm{dyn} / \mathrm{cm}^{2}$ (see fig. 2d). Because PMN had shown higher adhesion at 0.25 dyn $/ \mathrm{cm}^{2}$ (see fig. 2b), we also used two higher concentrations of monocytes and PMN $\left(5 \times 10^{5}\right.$ and $1 \times 10^{6}$ cells $\left./ \mathrm{ml}\right)$ for static coincubation to exclude concentration-dependent effects. After $4 \mathrm{~h}$, the cocultures were washed with buffer and labeled with $\mathrm{mAb}$ against ICAM-1 and E-selectin for flow cytometry. For comparison, nonactivated and LPS-activated HUVEC monocultures were used. To investigate whether the interactions of monocyte cell surface receptors with their endothelial counterparts alone were sufficient to upregulate ICAM-1 and E-selectin, or whether the activation of additional intracellular pathways in the monocyte was mandatory to induce the endothelial response to adhesion, monocytes were pretreated with $2.5 \mu \mathrm{g} / \mathrm{ml}$ brefeldin A (Sigma) to block intracellular transport of secretory proteins without altering the cell membrane [18]. After washing, the brefeldin-treated monocytes $\left(2.5 \times 10^{5}\right.$ cells $\left./ \mathrm{ml}\right)$ were also used for static coincubation.

Endothelial Response to Leukocyte Adhesion
Effects of PMN and Monocyte Adhesion on Subsequent PMN Adhesion during Reperfusion

HUVEC were incubated with PMN or monocytes at $2.5 \times 10^{5}$ cells/ml under static conditions as described above. Thereafter, the coverslip was inserted into the flow chamber and reperfused with fluorescence-labeled PMN $\left(10^{6}\right.$ cells $\left./ \mathrm{ml}\right)$ for $10 \mathrm{~min}$ at 2 dyn/ $\mathrm{cm}^{2}$. Fluorescence labeling was achieved by incubation of PMN with calcein-AM $(10 \mu \mathrm{g} / \mathrm{ml}$ for $30 \mathrm{~min}$ in the dark, Molecular Probes, Eugene, Oreg., USA). In order to discriminate PMN adhesion during reperfusion from those PMN or monocytes that had already adhered during static coincubation, the labeled PMN were selectively visualized by fluorescence microscopy (filter I3, Leica). To determine the molecular determinants for PMN adhesion during reperfusion, blocking $\mathrm{mAb}$ against $\mathrm{E}$-selectin $(\mathrm{P} 2 \mathrm{H} 3$ Chemicon International, Temecula, Calif., USA), L-selectin (DREG-56, BD-Biosciences Pharmingen) and CD18 (IB-4, Ancell, Bayport, Minn., USA) were added to the cocultures at $10 \mu \mathrm{g} /$ $\mathrm{ml} 30 \mathrm{~min}$ prior to the reperfusion assay. The nonspecific, nonblocking clone HP6069 (BD-Biosciences Pharmingen) was used as a control.

\section{Flow Cytometry}

Cell surface antigen expression of 5,000 HUVEC, PMN or monocytes per sample was determined by flow cytometry (FACSort $^{\mathrm{TM}}$, Becton Dickinson). Leukocyte subpopulations or HUVEC were identified using forward and side scatter properties and staining with saturating amounts of fluorochrome-conjugated $\mathrm{mAb}$ against CD45, CD14 and CD15 for the leukocyte subpopulations or $\mathrm{mAb}$ against E-selectin, ICAM-1 and VCAM-1 for HUVEC. Matching isotype controls were used to define the setup of the instrument.

\section{Statistics}

Adhesion of leukocyte subpopulations at different shear stress was analyzed from the mean of 5 randomly chosen fields of view of 4 experiments for each experimental condition. Effects of adherent leukocytes from 6 experiments on subsequent PMN adhesion during reperfusion were examined in a similar way. Adhesion molecule expression was measured from median fluorescence intensities (MFI), calculated from 5,000 events detected by the flow cytometer for each sample of 6 experiments. Differences between shear stress levels as well as differences between untreated and pretreated HUVEC were analyzed by paired t tests. A $p$ value $<0.05$ after Bonferroni-Holm correction was considered significant. Data are presented as means and standard error of the mean, unless stated otherwise. All analyses were performed using the statistical software package JMP (SAS Institute Inc., Cary, N.C., USA).

\section{Results}

\section{Adhesion Molecule Expression on HUVEC and Leukocyte Subpopulations}

Endothelial cell culture resulted in nonactivated HUVEC with an intact upregulation of endothelial cell adhesion molecules following LPS activation (fig. 1a). As shown in figure $1 \mathrm{~b}$, cell separation of PMN and mono- 


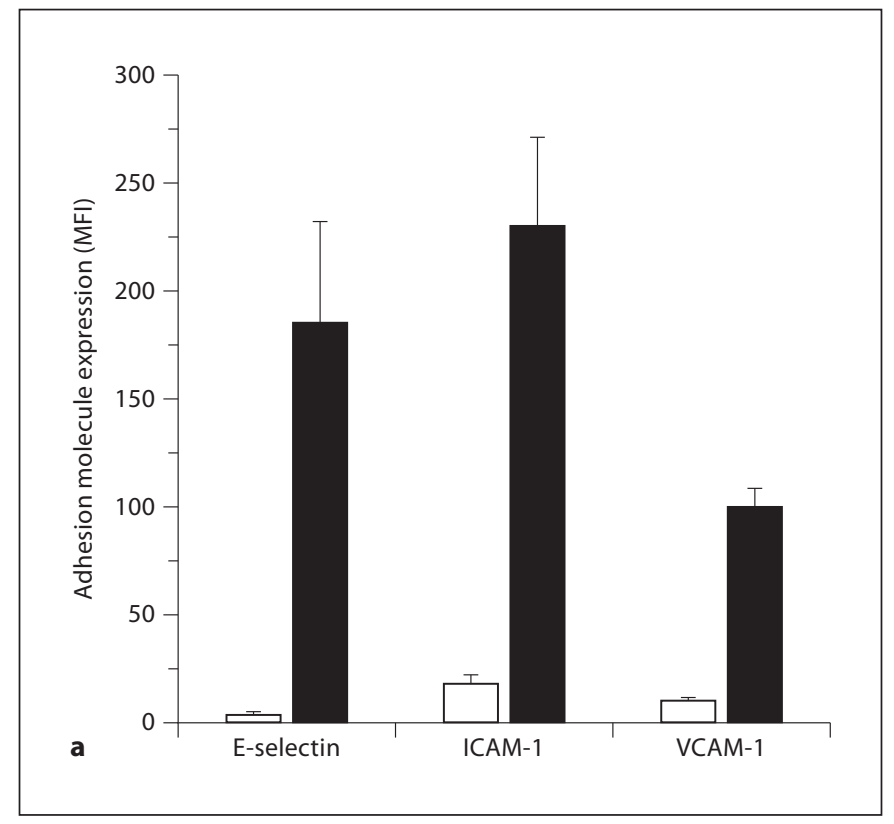

Fig. 1. Adhesion molecule expression on isolated cells. a Expression of endothelial cell adhesion molecules on nonactivated (white column) and LPS-activated HUVEC (100 ng/ml, 4 h; black column). b Expression of leukocyte adhesion molecules on nonactivated PMN (white column) and monocytes (light grey column)

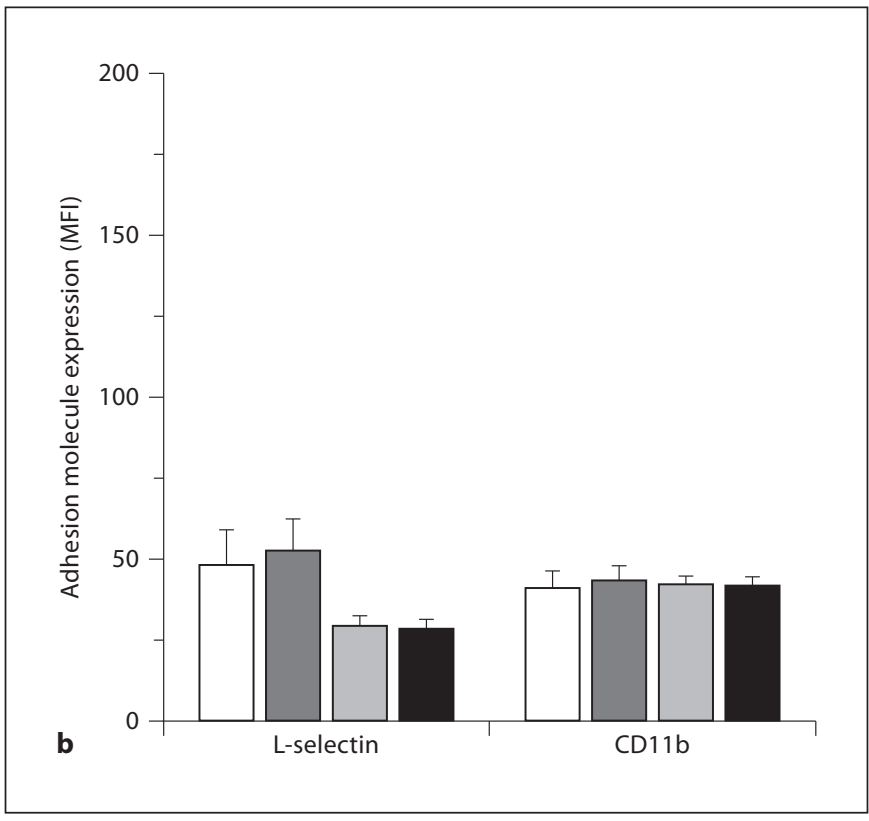

from whole blood in comparison to nonactivated isolated PMN (dark grey column) and monocytes (black column) after cell separation and rewarming. Results are given as means and standard error from 4 experiments.
Fig. 2. Effects of LPS activation and shear stress on leukocyte-endothelial interactions. a Firm adhesion of nonactivated PMN to HUVEC with and without LPS activation $(100 \mathrm{ng} / \mathrm{ml}, 4 \mathrm{~h})$ at $2 \mathrm{dyn} / \mathrm{cm}^{2}$. b Firm adhesion of nonactivated PMN to nonactivated HUVEC at 2 and 0.25 dyn/ $\mathrm{cm}^{2}$. c Firm adhesion of nonactivated monocytes to HUVEC with and without LPS activation (100 ng/ml, $4 \mathrm{~h}$ ) at $2 \mathrm{dyn} /$ $\mathrm{cm}^{2}$. d Firm adhesion of nonactivated monocytes to nonactivated HUVEC at 2 and $0.25 \mathrm{dyn} / \mathrm{cm}^{2}\left({ }^{*} \mathrm{p}<0.05\right.$; paired t test; $\mathrm{n}=4)$.

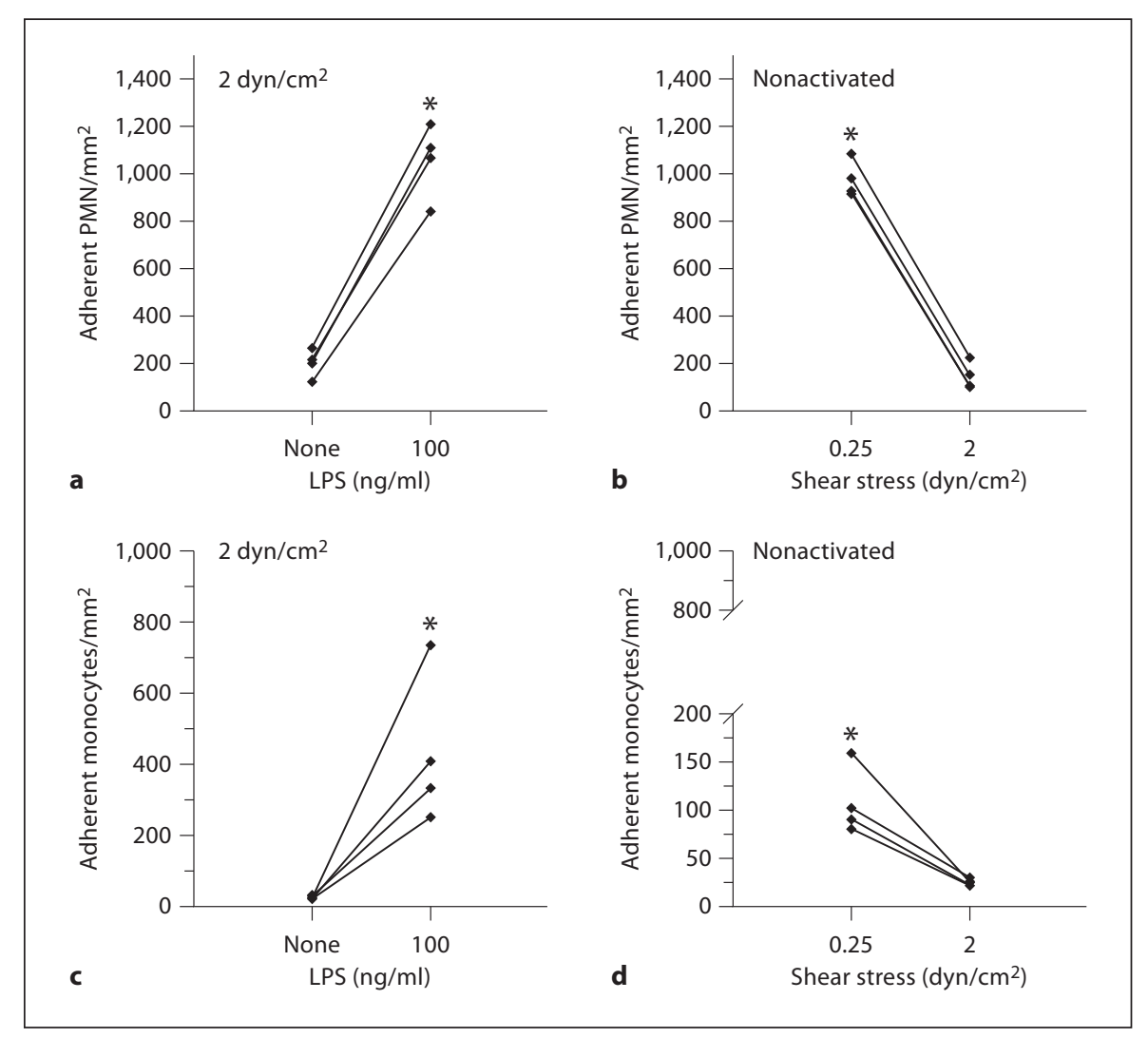




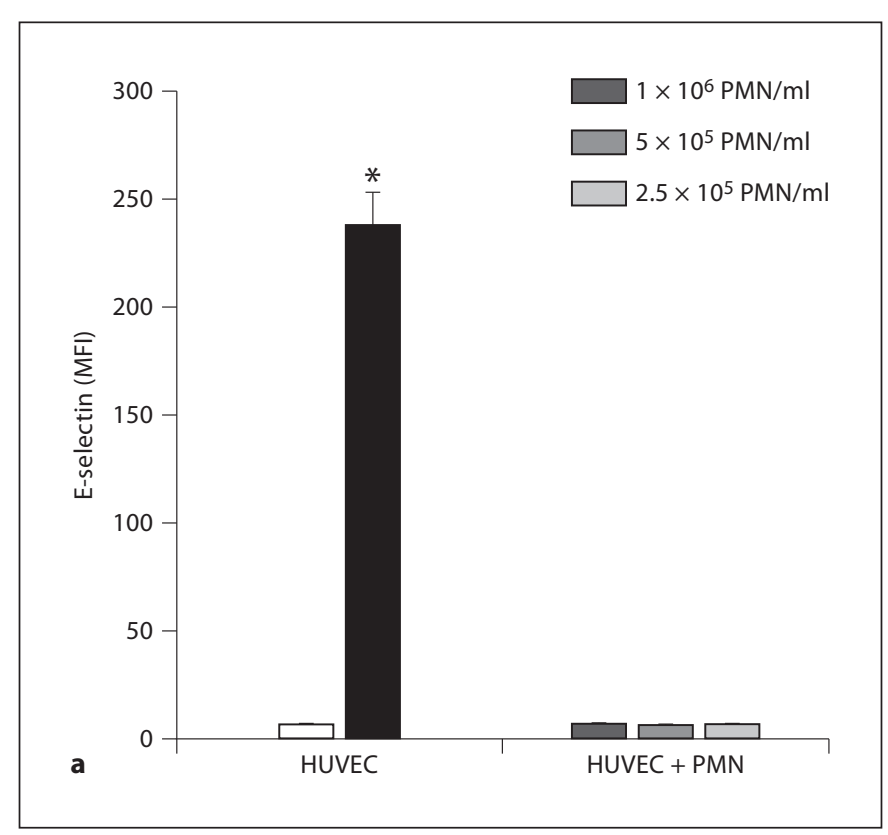

Fig. 3. Induction of E-selectin (a) and ICAM-1 (b) on HUVEC after static adhesion of nonactivated PMN. Adhesion molecule expression as determined by flow cytometry in HUVEC monocultures without (white column) and with LPS activation (100 ng/ $\mathrm{ml}, 4 \mathrm{~h}$; black column). Grey columns represent adhesion mole-

cytes yielded resting leukocytes without unintended activation of leukocyte adhesion molecules when compared to nonactivated leukocytes from whole blood.

\section{Effects of Shear Stress on Leukocyte Adhesion}

Under a shear stress of $2 \mathrm{dyn} / \mathrm{cm}^{2}$, activation with LPS was required to induce relevant adhesion of PMN or monocytes ( $p<0.05$; fig. 2 ). When shear stress was reduced from 2 to $0.25 \mathrm{dyn} / \mathrm{cm}^{2}$, however, adhesion of PMN and monocytes increased significantly without additional LPS activation $(\mathrm{p}<0.05)$. Regarding the magnitude of increase, reduced shear stress induced a 6 -fold increase in PMN adhesion, similar to the effects of LPS at $2 \mathrm{dyn} / \mathrm{cm}^{2}$. Although monocyte adhesion did not increase to the same extent, it did increase 4.5 -fold (fig. 2).

\section{Different Effects of PMN and Monocyte Adhesion on \\ Endothelial Cell Adhesion Molecule Expression}

Coincubation of nonactivated HUVEC with three different concentrations of nonactivated PMN under static conditions for $4 \mathrm{~h}$ did not upregulate E-selectin or ICAM1 when compared to the basal expression in nonactivated HUVEC monocultures (fig. 3). In contrast, the coincubation of nonactivated HUVEC with nonactivated mono-

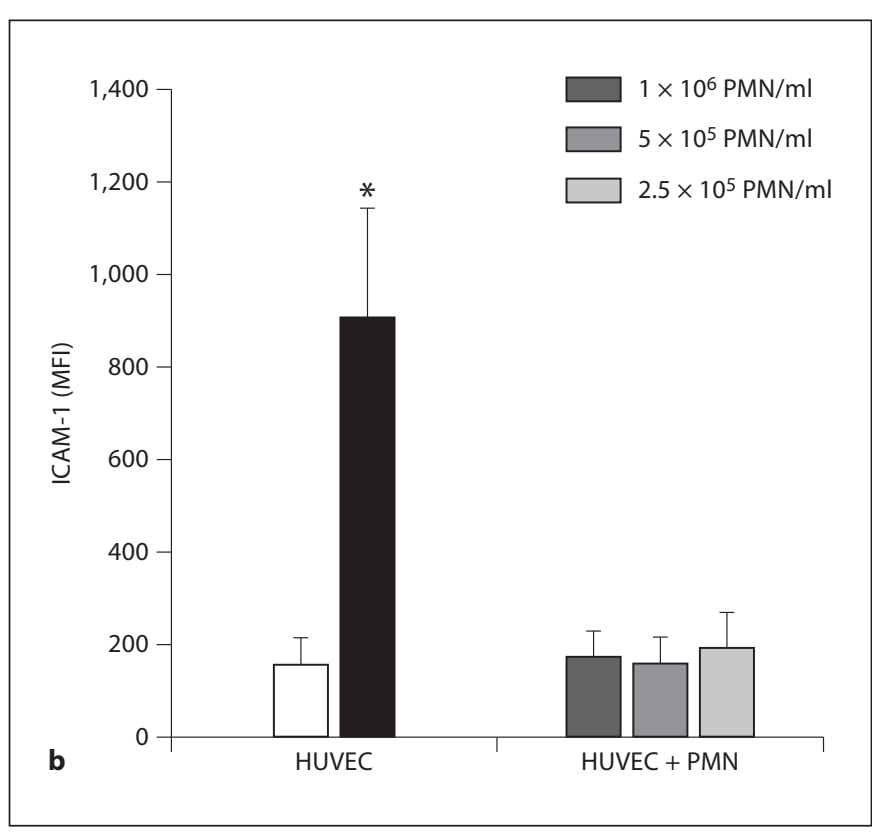

cule expression on HUVEC/PMN cocultures after $4 \mathrm{~h}$ of coincubation with varying PMN concentrations under static conditions. Results given as means and standard error from 6 experiments ( ${ }^{*} \mathrm{p}<0.01$ vs. nonactivated HUVEC monoculture; paired t test).

cytes significantly increased the expression of both adhesion molecules ( $\mathrm{p}<0.01$, fig. 4$)$ to a degree comparable to the effects of $100 \mathrm{ng} / \mathrm{ml}$ LPS in HUVEC monocultures. This increase was independent of the monocyte concentration (fig. 4) and was also observed even when nonactivated HUVEC were incubated with PMN suspensions that contained only $5 \%$ contaminating monocytes (fig. 5). Pretreatment of monocytes with brefeldin A inhibited the endothelial response to monocyte adhesion completely (fig. 4).

\section{Different Effects of PMN and Monocyte Adhesion on Subsequent PMN Adhesion during Reperfusion}

When compared to nonactivated HUVEC monocultures, coincubation with PMN did not increase subsequent adhesion of fluorescently labeled PMN during reperfusion at $2 \mathrm{dyn} / \mathrm{cm}^{2} 4 \mathrm{~h}$ later (fig. 6a). In contrast, coincubation of HUVEC with nonactivated monocytes largely increased subsequent PMN adhesion during reperfusion when compared to nonactivated HUVEC that were not pretreated with monocytes prior to the reperfusion assay (fig. 6b). Addition of mAb against E-, L-selectin or CD18 to HUVEC/monocyte cocultures during reperfusion inhibited adhesion of reperfused PMN by $90 \%$ (fig. 6b). 


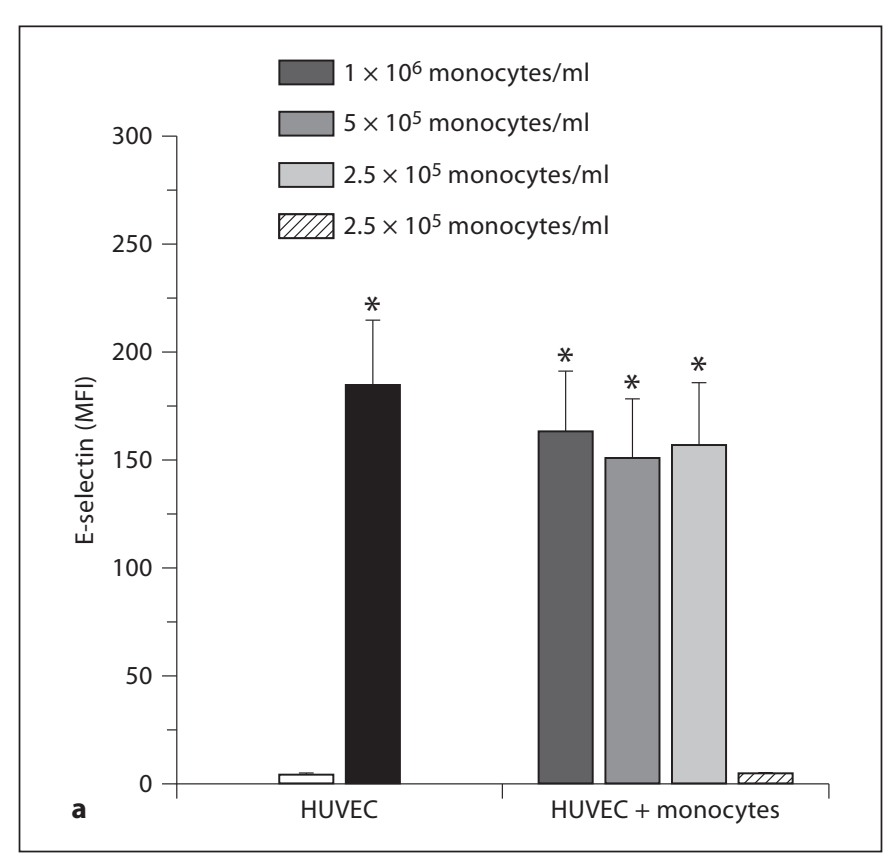

Fig. 4. Induction of E-selectin (a) and ICAM-1 (b) on HUVEC after static adhesion of nonactivated monocytes. Adhesion molecule expression as determined by flow cytometry in HUVEC monocultures without (white column) and with LPS activation (100 ng/ml, 4 h; black column). Grey columns represent adhesion molecule expression on HUVEC/monocyte cocultures after $4 \mathrm{~h}$

\section{Discussion}

The increased adhesion of both leukocyte subpopulations to the endothelium at $0.25 \mathrm{dyn} / \mathrm{cm}^{2}$ in the absence of concurrent inflammatory activation indicates that low shear stress is an autonomous trigger for leukocyte adhesion. Upon adhesion, however, only adherent monocytes induced pronounced upregulation of endothelial cell adhesion molecules, whereas PMN did not. Similar effects were seen in PMN preparations that contained 5\% monocytes, indicating that the normal monocyte blood count is sufficient to induce such activation. Most importantly, this activation resulted in a large increase in subsequent PMN adhesion during reperfusion. These findings provide the first in vitro evidence for the combined effects of low shear stress and adhesion on endothelial cell activation in the absence of any additional activator and suggest that their combination has the capacity to trigger a prolonged endothelial activation with substantial consequences for subsequent leukocyte adhesion at reperfusion. Direct comparison further showed that it is the monocyte, and not the PMN, that represents the responsible entity.

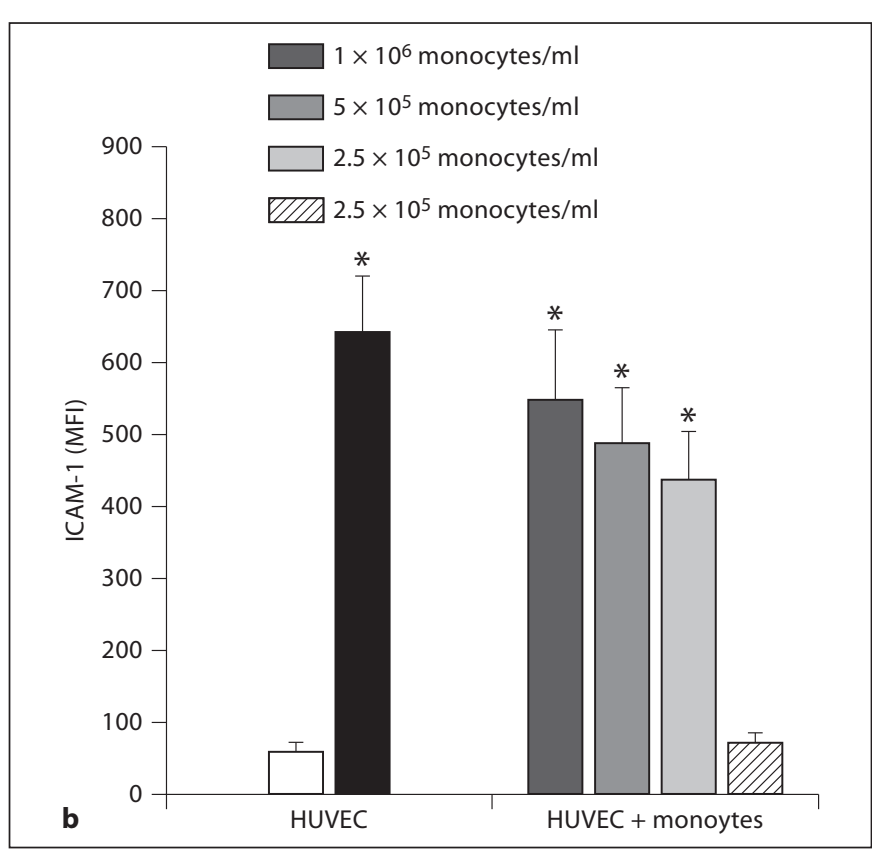

of coincubation with different monocyte concentrations under static conditions. Hatched column represents a subgroup of HU$\mathrm{VEC} /$ monocyte cocultures with $2.5 \times 10^{5}$ monocytes $/ \mathrm{ml}$ pretreated with brefeldin A prior to coincubation. Results are given as means and standard error from 6 experiments ( ${ }^{*} p<0.01$ vs. nonactivated HUVEC monoculture; paired t test).
Apart from their primary adhesion to activated endothelium, leukocytes can adhere to already adherent leukocytes. This process is called secondary capture and relies in major parts on interactions between L-selectin and its receptor P-selectin glycoprotein ligand (PSGL)-1, both of which are expressed constitutively on all leukocytes [3]. As documented by the large inhibitory effect of blocking L-selectin in our experiments, improved secondary capture played an important role for total PMN accumulation during reperfusion. In HUVEC/monocyte cocultures, blockade of L-selectin decreased adhesion by $90 \%$, whereas only $40 \%$ inhibition is seen in the same model on LPS-activated HUVEC monocultures [17]. Notwithstanding, only adherent monocytes but not PMN increased subsequent adhesion during reperfusion indicating that leukocyte-leukocyte interactions alone were not sufficient to aggravate leukocyte accumulation unless Eselectin and ICAM-1 were upregulated by monocyte-related endothelial activation. This is also reflected by the large inhibition in PMN adhesion seen in reperfused HUVEC/monocyte cocultures with E-Selectin blockade. As shown by the inhibiting properties of CD $18 \mathrm{mAb}$, the 


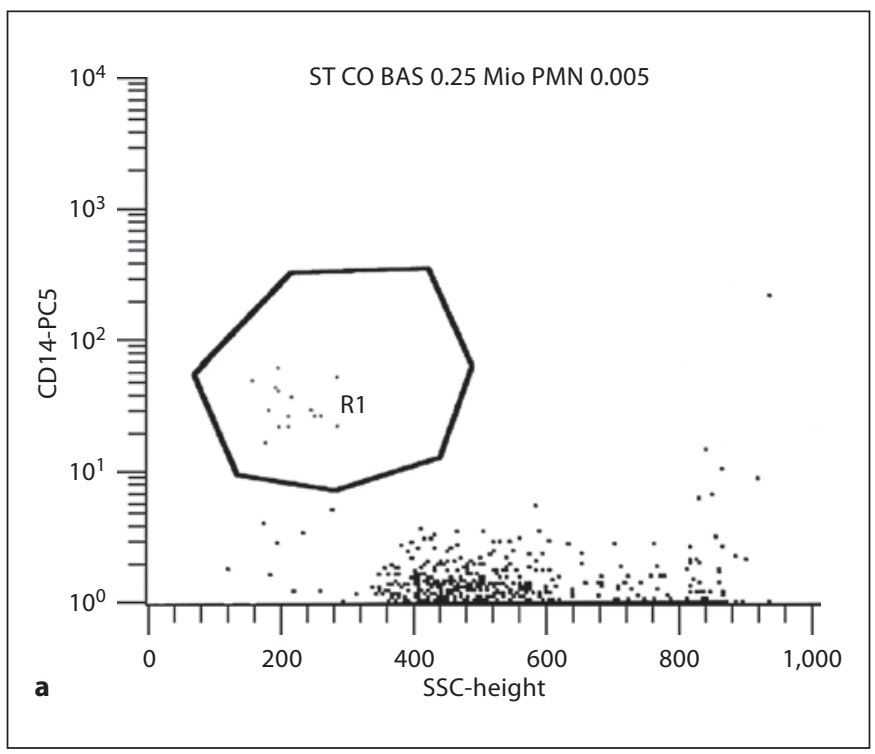

Fig. 5. Effect of low monocyte concentrations on endothelial cell adhesion molecule expression. Results from 3 experiments with static coincubation $(4 \mathrm{~h})$ of nonactivated HUVEC with nonactivated $\mathrm{PMN}$ suspension and different admixture of contaminating monocytes. a, b Original plots from flow cytometry showing contamination with $0.2 \%$ CD14+ monocytes (a) and 5\% CD14+ monocytes in gate R1 (b). c Expression of E-selectin and ICAM-1 in HUVEC/PMN cocultures with $0.2 \%$ contaminating monocytes (light grey column) and 5\% contaminating monocytes (dark grey column). For comparison, the black column represents the expression on HUVEC monocultures after maximal LPS activation $(100 \mathrm{ng} / \mathrm{ml}, 4 \mathrm{~h})$. Expression is given as relative increase in relation to the expression detected on nonactivated HUVEC monocultures (indicated by a broken line).

binding of leukocyte integrins to their endothelial receptors (such as ICAM-1) was necessary to translate rolling into firm adhesion. Failure to upregulate endothelial adhesion molecules thus appeared responsible for the lacking effect of adherent PMN on subsequent PMN-adhesion during reperfusion.

In contrast to our observations, other investigators suggested that adherent PMN may directly induce endothelial activation through the binding of CD11a and CD11b to ICAM-1 [11]. This assumption was based on the finding that activated PMN increased the production of reactive oxygen species (ROS) in adjacent endothelial
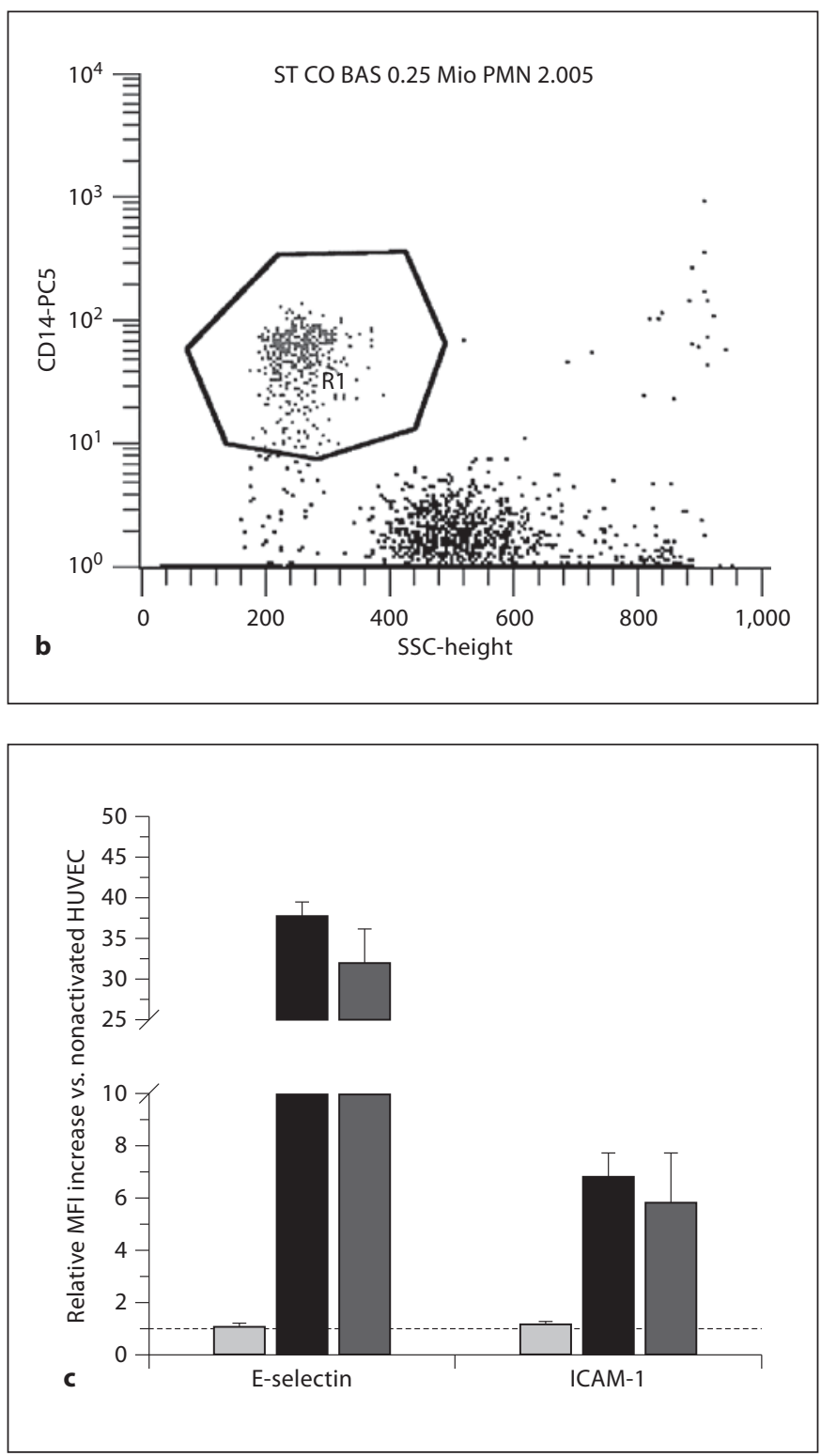

cells, regardless of whether living or ethanol-fixed dead PMN were used. In a subsequent study, however, endothelial peroxynitrite levels and adhesion molecule expression increased only when activated PMN were used, whereas nonactivated PMN showed no effect [12]. In agreement with our results, these findings indicate that PMN must be costimulated with both an inflammatory mediator and an adhesive substrate to elicit a full endothelial response to adhesion, whereas monocytes induce profound endothelial cell activation upon adhesion even in the absence of an additional activator. Apart from simply enabling firm adhesion, interactions of $\beta_{2}$ and $\beta_{1}$-in- 


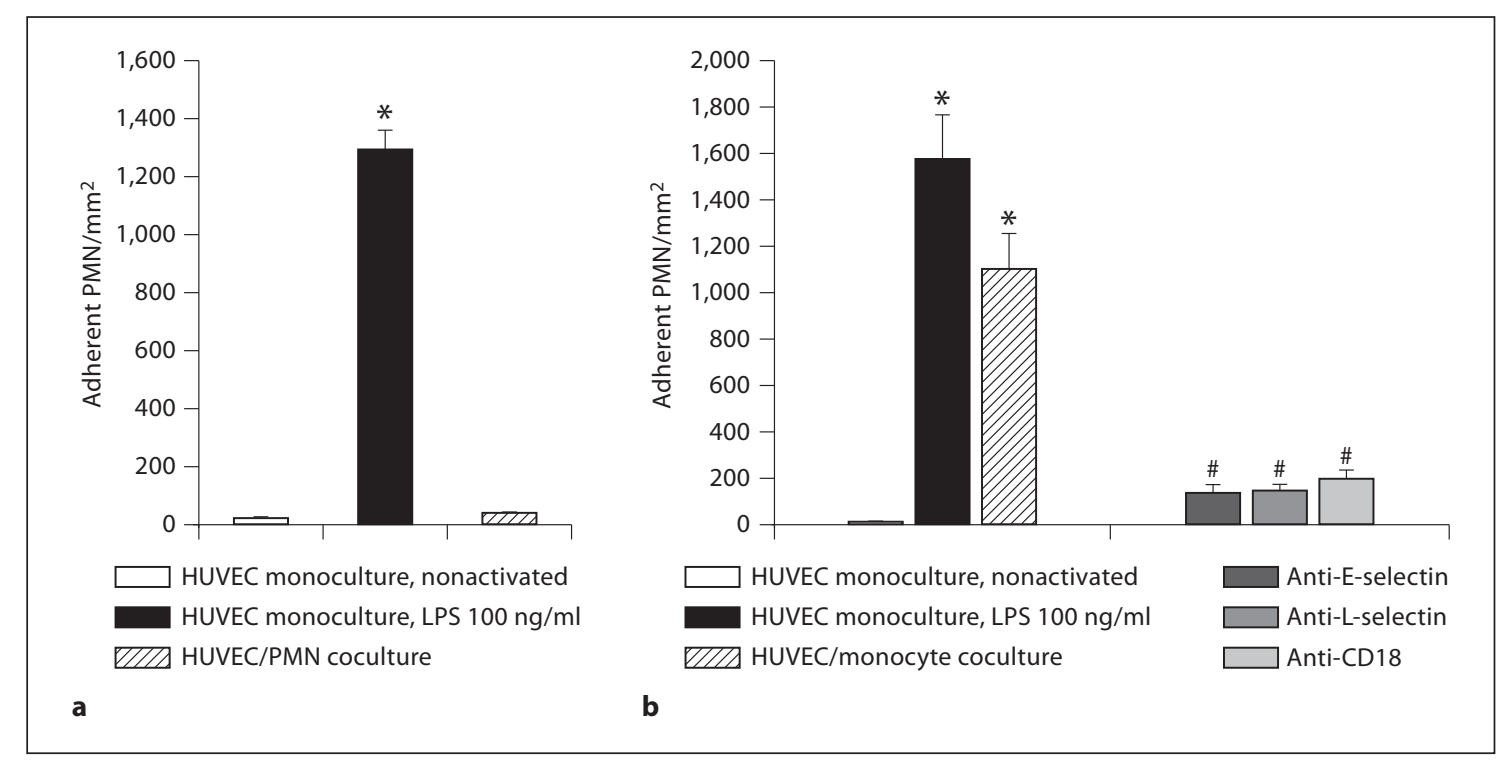

Fig. 6. Effects of static adhesion of PMN and monocytes on PMN adhesion during reperfusion. Following $4 \mathrm{~h}$ of static coincubation of nonactivated HUVEC with nonactivated PMN or monocytes, the cocultures were reperfused with fluorescently labeled PMN at $2 \mathrm{dyn} / \mathrm{cm}^{2}$. For comparison, HUVEC monocultures with and without LPS activation were also perfused with fluorescently la- beled PMN. In a subset of experiments, E-selectin, L-selectin and CD18 were blocked with functional blocking antibodies. Results are given as means and standard error from 6 experiments $\left({ }^{*} \mathrm{p}<\right.$ 0.01 vs. nonactivated HUVEC monoculture; ${ }^{*} \mathrm{p}<0.01$ vs. HUVEC monocyte coculture). tegrins with their endothelial receptors (such as ICAM-1 and VCAM-1) initiate a multitude of post-receptor signaling pathways in leukocytes and endothelial cells $[3,5$, 19]. In an earlier study on monocyte-endothelial interaction, endothelial activation depended on interactions of $\mathrm{CD} 1 \mathrm{lb}$ with the endothelium [15]. Our results show that the binding of $\beta_{2}$-integrins such as CD11b to their endothelial counterreceptors, on its own, is not sufficient to induce endothelial activation. This is because these integrins are expressed on PMN and mononcytes, whereas the upregulation of E-selectin occurred after monocyte adhesion only.

Even ligations of other monocyte-specific $\beta_{1}$-integrins (such as very late antigen (VLA)-4) are not solely responsible for endothelial activation since blockade of intracellular protein transport with brefeldin A abolished the upregulation of endothelial cell adhesion molecules in our experiments. This finding and the contrasting effects of adherent PMN and monocytes indicate that the endothelial response to adhesion depends on important differences in postadhesion signaling between both leukocyte subpopulations. Of the large proinflammatory armentarium of monocytes, cytokine-associated pathways seem to be reasonable candidates as integrin-induced outside-in signaling induces stabilization of cytokine mRNA, particularly interleukin (IL)- $1 \beta$ and tumor necrosis factor (TNF)- $\alpha$, which have been shown to activate NF- $\kappa \mathrm{B}$ and E-selectin in endothelial cells following adhesion in vitro $[5,13-15,19]$. Nevertheless, although IL-1 and TNF- $\alpha$ are potent activators, additional mechanisms seem to be involved in sustained endothelial activation following monocyte adhesion $[14,15]$. Inhibiting monocyte adhesion by blocking CD11b, for instance, attenuates E-selectin expression by $80 \%$, whereas only $50 \%$ inhibition is seen with TNF- $\alpha$ blockade [15]. Additionally, IL-1 and TNF- $\alpha$ upregulate E-selectin for only $4 \mathrm{~h}$, whereas monocyte adhesion results in sustained upregulation [14]. We did not look for random candidates of interest in our experiments because bidirectional signaling during monocyte-endothelial interaction is imbedded in a system with substantial complexity and overlapping pathways $[5,19]$. In the light of the current knowledge, however, some speculation may be allowed. Among the various chemokine-dependent pathways involved in monocyte-endothelial adhesion, interactions of CC-chemokine ligand (CCL)-2 with its monocyte chemokine receptor (CCR)-2 likely could be involved. When presented on activated endothelium, CCL-2 favors monocyte 
adhesion. Beyond its contribution to monocyte recruitment, CCL-2 has also been shown to amplify endothelial activation in interaction with TNF- $\alpha$ and is regarded as a key regulator of endothelial dysfunction in atherosclerosis and diabetes [20-22]. Most importantly, there is the first evidence that CCR-2-expressing monocytes regulate the migration of neutrophils into inflamed or postischemic lungs [23, 24]. Limited by the technical difficulties of the in vivo setting, the latter observations did not provide a detailed insight into the mechanisms involved and were regarded preliminary as yet [23]. In combination with our results, however, they suggest that the CCL2/CCR-2 axis might be a key regulator of monocyte-dependent reperfusion injury that should be the subject of further study. Regarding the transient effect of monocyte-derived cytokines and the more sustained effects of monocyte adhesion on endothelial activation [20,21], it appears possible that monocyte-derived cytokines first upregulate endothelial CCL-2 which, in turn, binds to its ligand CCR-2 on the monocyte and translates initial activation into a sustained endothelial response to monocyte adhesion.

In order to examine the interplay of shear stress, leukocyte adhesion and endothelial activation during low flow and reperfusion, we used a standardized flow-chamber model to avoid the overlapping effects of shear stress, ischemia and inflammation, as they may arise in animal models. Clearly, this artificial in vitro model has other limitations as it cannot simulate all aspects of the microcirculation in an intact organism. For instance, we used HUVEC instead of microvascular endothelium to avoid the downregulation of adhesion molecules during multiple subpassages which would have been necessary to gain a sufficient number of microvascular monolayers for a comparative setting. Although HUVEC might express selectins at a higher density than microvascular endothelium [25], this does not seem to be functionally important; a direct comparison of microvascular and umbilical venous endothelium showed no relevant differences in a previous study on monocyte adhesion [13]. Accordingly, the effects of selectin blockade in our experimental setting closely resemble those that have been observed from the intact postcapillary microcirculation in vivo $[17,26]$. The use of leukocyte isolates might be regarded the most critical limitation of adhesion assays as it precludes the effects of other cell types from whole blood and bears the risk of unintended changes in L-selectin and CD $11 \mathrm{~b}$ expression during cell separation $[3,16]$. The use of different leukocyte subsets, however, was mandatory to delineate important differences between PMN and monocytes

Endothelial Response to Leukocyte Adhesion that had not yet been described. Most importantly, the modified separation technique in our experiments did not alter leukocyte adhesion molecule expression as documented by the direct comparison of isolated PMN and monocytes to their counterparts in whole blood. While previous studies on shear stress and adhesion have been criticized for possible alteration of leukocyte adhesion molecules during cell separation [3], this concern does not apply to our experimental setup.

When cell suspensions are used instead of whole blood, differences in shear stress must be kept in mind to avoid misinterpretation. Shear stress is the product of viscosity and shear rate; the latter determined by the flowdependent velocity gradient near the (vascular) wall [27]. Because of plasma proteins and red blood cells, viscosity is higher in whole blood than in aqueous cell suspension in vitro. In vivo, viscosity further varies with hematocrit and shear rate. At a given shear rate, these rheological properties of whole blood increased shear stress by 3-5 times when compared to our model [28]. For interpreting adhesion assays, these differences between Newtonian cell suspensions and non-Newtonian whole blood should be considered since leukocytes usually fail to adhere at shear stresses $>4-10$ dyn $/ \mathrm{cm}^{2}$ in vitro while they might still become adherent in vivo [3]. The reason for this discrepancy is largely due to the interaction of adhesion molecules with shear-induced deformation of the leukocyte cell membrane and its balance with the distracting forces of flow velocity. Although shear rate and shear stress are closely linked, shear rate is predominantly determined by flow velocity. As a decrease in flow velocity leads to an increased residence time of leukocytes at the endothelium, it will expand the time available for bond formation and thereby increase the chances of a cell to become adherent. At the same time, however, decreased shear stress results in decreased torque followed by a decreased deformation of the leukocyte. As a consequence, the contact area between the interacting cells is decreased, which reduces the number of available binding sites $[29,30]$. While integrin-dependent adhesion is promoted by increased residence times, torque is of critical importance for shortlived selectin interactions. Because selectin-mediated rolling requires the formation of new bonds before previous bonds have become released, a shear threshold of 0.5 $\mathrm{dyn} / \mathrm{cm}^{2}$ is required to maintain rolling interactions [31]. Increasing the surface density of available binding sites compensates for this effect [29, 31]. In this regard, the importance of shear stress versus shear rate is shown by studies that reported an improved adhesion when viscosity was increased at given shear rates $<800 \mathrm{~s}^{-1}[30,32]$. 
Although absolute values of shear stress in vivo are not directly comparable to shear stress in vitro for the reasons mentioned above, the consequences of decreasing shear rate are similar. At $2 \mathrm{dyn} / \mathrm{cm}^{2}$, the shear rate in the flow chamber is $285 \mathrm{~s}^{-1}$ which is equal to a shear stress of 6-10 $\mathrm{dyn} / \mathrm{cm}^{2}$ at normal blood viscosity in vivo. At $0.25 \mathrm{dyn} /$ $\mathrm{cm}^{2}$, the shear rate is $35 \mathrm{~s}^{-1}$. In rats, a decrease from 400 to $50 \mathrm{~s}^{-1}$ resulted in 3-fold increased leukocyte-endothelial interactions in mesenteric venules [9]. In the pulmonary microcirculation even a small reduction from 266 to $188 \mathrm{~s}^{-1}$ induced a $20 \%$ increase in leukocyte accumulation [10]. Since shear rate depends on flow velocity, it depends on vessel size and blood flow. Similar to our experimental setup, shear rate was decreased in the mentioned animal studies by decreasing flow. Hence, apart from altered shear forces, altered mass transport of soluble mediators or nutrients might have also contributed to the observed adhesion behavior. This is illustrated by an earlier study in which the reduced wash-out of leukotriene B4 contributed to shear-rate-dependent leukocyte adhesion in mesenteric venules after graded occlusion of the arterial circuit [7]. In our experiments, we related leukocyte adhesion to shear stress as it implies all hydrodynamic forces that interact with leukocyte adhesion. However, because of the interaction of cell adhesion with shear forces and flow described above, it appears likely that the reduction of shear rate and flow is the major contributor that triggers adhesion at low shear stress.

Regardless of its hydrodynamic effects on cell interactions, shear stress is a key regulator of endothelial cell function and morphology [33]. While earlier studies reported upregulation of ICAM-1, CCL-2 and increased leukocyte adhesion when static cultures were subjected to flow [34, 35], it has meanwhile become accepted that these findings were not related to a proinflammatory effect of shear stress itself, but to the abrupt changes imposed $[33,36]$. Apart from shortening residence times, maintaining laminar shear stress protects against leukocyte adhesion by stimulating the endothelial-dependent synthesis of anti-inflammatory transcription factors, kinases, prostacyclin and nitric oxide while ROS-mediated activation of proinflammatory kinases and NF- $\kappa \mathrm{B}$ is inhibited $[9,10,33,37]$. As most of these effects did not play a role in our experimental setting, our results indicate that the hydrodynamic effects of shear stress on residence times alone are sufficient to induce adhesion and endothelial activation. Because all HUVEC were grown under classic static culture conditions before the adhesion assays, even $0.25 \mathrm{dyn} / \mathrm{cm}^{2}$ did not represent a decrease in shear stress in relation to the prior conditions, and should not have attenuated the expression of anti-inflammatory proteins. When static endothelial cell cultures were exposed to flow or TNF- $\alpha$ in other studies, an increased expression of CCL-2, ICAM-1 and increased leukocyte adhesion were observed in comparison to shear-conditioned endothelium [34-36]. As shown by the reperfusion experiments, this does not explain our findings. Following static coincubation of HUVEC with PMN or monocytes, adhesion molecule expression and adhesion during reperfusion only increased following pretreatment with monocytes, but not in both types of cocultures. As Matharu et al. [36] demonstrated in a detailed study on endothelial cell function under varying conditions of flow, the ability to capture flowing PMN following reinstitution of flow lasts from $1-3 \mathrm{~h}$ after flow reduction only, and depends on a ROS-mediated increase in platelet (P)-selectin expression. In our study, the reperfusion experiments were conducted at a later time point after $4 \mathrm{~h}$ of static coincubation. P-selectin was not assessed in these experiments as it does not play a role in leukocyte rolling after $4 \mathrm{~h}$ of endothelial activation in humans [17]. Unlike rodents, humans and primates are not able to sustain endothelial P-selectin expression beyond the very first minutes of acute inflammation because of a lack in transcriptional regulation $[3,38]$. Although P-selectin is a key regulator of early reperfusion injury [2], we had to choose a longer duration for coincubation to examine firm adhesion at the time of maximal expression of Eselectin and ICAM-1, instead of initial capture only. Accordingly, Matharu et al. [36] noted only a transient increase in P-selectin-dependent rolling interactions, whereas we observed a profound increase in firm adhesion after a 4-hour pretreatment with monocytes. Regarding the functional role of endothelial derived P-selectin, it also seems intriguing that platelet, but not endothelial P-selectin has been shown to contribute to leukocyte-related organ dysfunction of the kidneys, lungs and liver, even in rodents [39-41]. Regarding the reported hyperresponsiveness of static HUVEC to TNF- $\alpha$, this observation might in itself represent an in vitro phenomenon. While shear conditioning at $20 \mathrm{dyn} / \mathrm{cm}^{2}$ nearly abolished the endothelial response to TNF- $\alpha$ in vitro, TNF- $\alpha$ frequently increases adhesion molecule expression and leukocyte adhesion in postcapillary venules in vivo [26]. Although our conclusions are derived from a simplified in vitro system, the validity of the parallel plate flow chamber as a model for cell interactions in vivo has been shown by direct comparison in an animal study on integrin function [42]. Finally, the relevance of our findings is strengthened by studies on temporal and spatial leuko- 
cyte extravasation in reperfused lungs. In these models of noninfectious pulmonary inflammation, lung injury was shown to be biphasic with an early monocyte-dependent phase and a later neutrophil-dependent phase. In addition, neutrophil extravasation occurred adjacent to extravasated monocytes and was inhibited by monocyte depletion $[23,43]$.

Taken together, this study demonstrates that low shear forces, as they occur in the earliest phase of I/R and shock [44-46], induce adhesion in the absence of additional inflammatory activation or hypoxia. In our experimental setting, the decrease in shear rate and the consecutively increased residence time of leukocytes at the endothelium appeared to be the key factors for adhesion at low shear stress. In vivo, other mechanisms such as an altered nitric oxide production are likely to contribute, especially when shear-conditioned endothelium is subjected to an abrupt decrease in shear stress. Although these mechanisms may further enhance adhesion, we provide the first evidence that the combination of low shear stress and monocyte adhesion alone has the capacity to initiate a profound inflammatory response as an important trigger for subsequent PMN accumulation during reperfusion. In so far as shear stress depends on complex interactions between systemic blood flow, vasomotor tone and local arteriovenous pressure gradients, it cannot be predicted from global hemodynamic measurements and may be decreased even when tissue oxygenation is pre- served or has been restored [44-47]. From a clinical point of view, our findings therefore mandate the need for microvascular resuscitation targets in addition to the controversially discussed thresholds of macrovascular hemodynamics and oxygen delivery [45]. As leukocyte accumulation has been shown to correlate with the degree of hemodynamic instability in sepsis models, decreased shear forces might not only contribute to leukocyte-related tissue damage in noninfectious reperfusion injury but also in septic shock [48-50]. From a researcher's perspective, our results indicate that more emphasis should be placed on the differential role of various leukocyte subsets during shock syndromes. Although the microvascular accumulation of neutrophils is numerically abundant during shock and I/R, monocytes may have an even more substantial influence on the development of endothelial dysfunction and subsequent leukocyte accumulation during reperfusion.

\section{Acknowledgments}

The authors thank Alice Mager and Christof Zanke, technical assistants, Department of Anaesthesiology and Intensive Care Medicine, Tübingen, Germany, for their help with the adhesion assays, and Martin Eichner Ph.D. from the Department of Biometry for his statistical expertise. The study was supported by a grant of the fortuene-programme to B. Nohé (project 777-0-0, Medical Faculty, University of Tübingen).

\section{References}

1 Mazzoni MC, Schmid Schonbein GW: Mechanisms and consequences of cell activation in the microcirculation. Cardiovasc Res 1996;32:709-719.

-2 Lefer DJ, Flynn DM, Anderson DC, Buda AJ: Combined inhibition of P-selectin and ICAM-1 reduces myocardial injury following ischemia and reperfusion. Am J Physiol 1996;271:H2421-H2429.

3 Zarbock A, Ley K: Neutrophil adhesion and activation under flow. Microcirculation 2009; 16:31-42.

4 Lawrence MB, Smith CW, Eskin SG, McIntire LV: Effect of venous shear stress on CD18-mediated neutrophil adhesion to cultured endothelium. Blood 1990;75:227-237.

5 Imhof BA, Urrand-Lions M: Adhesion mechanisms regulating the migration of monocytes. Nat Rev Immunol 2004;4:432444 .
6 Luscinskas FW, Kansas GS, Ding H, Pizcueta P, Schleiffenbaum BE, Tedder TF, Gimbrone MA, Jr.: Monocyte rolling, arrest and spreading on IL-4-activated vascular endothelium under flow is mediated via sequential action of L-selectin, beta 1-integrins, and beta 2-integrins. J Cell Biol 1994;125:14171427.

7 Bienvenu K, Russell J, Granger DN: Leukotriene $\mathrm{B} 4$ mediates shear rate-dependent leukocyte adhesion in mesenteric venules. Circ Res 1992;71:906-911.

-8 Bienvenu K, Granger DN: Molecular determinants of shear rate-dependent leukocyte adhesion in postcapillary venules. Am J Physiol 1993;264:H1504-H1508.

-9 Firrell JC, Lipowsky HH: Leukocyte margination and deformation in mesenteric venules of rat. Am J Physiol 1989;256:H1667-H1674.

10 Kuhnle GE, Kuebler WM, Groh J, Goetz AE: Effect of blood flow on the leukocyte-endothelium interaction in pulmonary microvessels. Am J Respir Crit Care Med 1995;152: 1221-1228.
11 Murota SI, Fujita H, Morita I, Wakabayashi Y: Adhesion molecule mediated endothelial cell injury elicited by activated leukocytes. Ann N Y Acad Sci 1995;748:133-147.

-12 Sohn HY, Krotz F, Zahler S, Gloe T, Keller M, Theisen K, Schiele TM, Klauss V, Pohl U: Crucial role of local peroxynitrite formation in neutrophil-induced endothelial cell activation. Cardiovasc Res 2003;57:804-815.

13 Belcher JD, Marker PH, Weber JP, Hebbel RP, Vercellotti GM: Activated monocytes in sickle cell disease: potential role in the activation of vascular endothelium and vaso-occlusion. Blood 2000;96:2451-2459.

14 Rainger GE, Wautier MP, Nash GB, Wautier JL: Prolonged E-selectin induction by monocytes potentiates the adhesion of flowing neutrophils to cultured endothelial cells. $\mathrm{Br}$ J Haematol 1996;92:192-199.

-15 Noble KE, Panayiotidis P, Collins PW, Hoffbrand AV, Yong KL: Monocytes induce Eselectin gene expression in endothelial cells: role of CD11/CD18 and extracellular matrix proteins. Eur J Immunol 1996;26:2944-2951. 
16 Nohe B, Zanke C, Johannes T, Kiefer T, Dieterich HJ. Effects of magnetic cell separation on monocyte adhesion to endothelial cells under flow. APMIS 2002;110:299-308.

- 17 Ploppa A, Schmidt V, Hientz A, Reutershan J, Haeberle HA, Nohe B: Mechanisms of leukocyte distribution during sepsis: an experimental study on the interdependence of cell activation, shear stress and endothelial injury. Crit Care 2010;14:R201.

18 Misumi Y, Misumi Y, Miki K, Takatsuki A, Tamura G, Ikehara Y: Novel blockade by brefeldin A of intracellular transport of secretory proteins in cultured rat hepatocytes. J Biol Chem 1986;261:11398-11403.

$\checkmark 19$ Abram CL, Lowell CA: The ins and outs of leukocyte integrin signaling. Annu Rev Immunol 2009;27:339-362.

20 Yang J, Park Y, Zhang H, Gao X, Wilson E, Zimmer W, Abbott L, Zhang C: Role of MCP1 in tumor necrosis factor-alpha-induced endothelial dysfunction in type 2 diabetic mice. Am J Physiol Heart Circ Physiol 2009; 297:H1208-H1216.

-21 Maus U, Henning S, Wenschuh H, Mayer K, Seeger W, Lohmeyer J: Role of endothelial MCP-1 in monocyte adhesion to inflamed human endothelium under physiological flow. Am J Physiol Heart Circ Physiol 2002; 283:H2584-H2591.

22 Mestas J, Ley K: Monocyte-endothelial cell interactions in the development of atherosclerosis. Trends Cardiovasc Med 2008;18: 228-232.

-23 Kreisel D, Nava RG, Li W, Zinselmeyer BH, Wang B, Lai J, Pless R, Gelman AE, Krupnick AS, Miller MJ: In vivo two-photon imaging reveals monocyte-dependent neutrophil extravasation during pulmonary inflammation. Proc Natl Acad Sci USA 2010;107: 18073-18078.

24 Maus UA, Waelsch K, Kuziel WA, Delbeck T, Mack M, Blackwell TS, Christman JW, Schlondorff D, Seeger W, Lohmeyer J: Monocytes are potent facilitators of alveolar neutrophil emigration during lung inflammation: role of the CCL2-CCR2 axis. J Immunol 2003;170:3273-3278.

25 Kvietys PR, Granger DN: Endothelial cell monolayers as a tool for studying microvascular pathophysiology. Am J Physiol 1997; 273:G1189-G1199.

26 Jung U, Ley K: Mice lacking two or all three selectins demonstrate overlapping and distinct functions for each selectin. J Immunol 1999;162:6755-6762.
27 Lawrence MB: In vitro flow models of leukocyte adhesion; in Ley K (ed): Physiology of Inflammation. Oxford, Oxford University Press, 2001, pp 204-221.

28 Kato T: Relation between blood viscosity and hematocrit in rabbits subjected to repeated treatment with endotoxin. Resuscitation 1991;21:61-66.

29 Lei X, Lawrence MB, Dong C: Influence of cell deformation on leukocyte rolling adhesion in shear flow. J Biomech Eng 1999;121: 636-643.

30 Smith ML, Smith MJ, Lawrence MB, Ley K: Viscosity-independent velocity of neutrophils rolling on P-selectin in vitro or in vivo. Microcirculation 2002;9:523-536.

31 Lawrence MB, Kansas GS, Kunkel EJ, Ley K: Threshold levels of fluid shear promote leukocyte adhesion through selectins $(\mathrm{CD} 62 \mathrm{~L}$, P, E). J Cell Biol 1997;136:717-727.

- 32 Taylor AD, Neelamegham S, Hellums JD, Smith CW, Simon SI: Molecular dynamics of the transition from L-selectin- to beta 2-integrin-dependent neutrophil adhesion under defined hydrodynamic shear. Biophys J 1996;71:3488-3500.

-33 Pan S: Molecular mechanisms responsible for the atheroprotective effects of laminar shear stress. Antioxid Redox Signal 2009;11: 1669-1682.

34 Nagel T, Resnick N, Atkinson WJ, Dewey CF, Jr, Gimbrone MA, Jr: Shear stress selectively upregulates intercellular adhesion molecule-1 expression in cultured human vascular endothelial cells. J Clin Invest 1994;94: 885-891.

35 Shyy YJ, Hsieh HJ, Usami S, Chien S: Fluid shear stress induces a biphasic response of human monocyte chemotactic protein 1 gene expression in vascular endothelium. Proc Natl Acad Sci USA 1994;91:4678-4682.

36 Matharu NM, McGettrick HM, Salmon M, Kissane S, Vohra RK, Rainger GE, Nash GB: Inflammatory responses of endothelial cells experiencing reduction in flow after conditioning by shear stress. J Cell Physiol 2008; 216:732-741.

- 37 Tsao PS, Buitrago R, Chan JR, Cooke JP: Fluid flow inhibits endothelial adhesiveness. Nitric oxide and transcriptional regulation of VCAM-1. Circulation 1996;94:1682-1689.

38 Yao L, Setiadi H, Xia L, Laszik Z, Taylor FB, McEver RP: Divergent inducible expression of P-selectin and E-selectin in mice and primates. Blood 1999;94:3820-3828.

- 39 Laschke MW, Dold S, Menger MD, Jeppsson B, Thorlacius H: Platelet-dependent accumulation of leukocytes in sinusoids mediates hepatocellular damage in bile duct ligationinduced cholestasis. Br J Pharmacol 2008; 153:148-156.
40 Singbartl K, Forlow SB, Ley K: Platelet, but not endothelial, P-selectin is critical for neutrophil-mediated acute postischemic renal failure. FASEB J 2001;15:2337-2344.

-41 Zarbock A, Singbartl K, Ley K: Complete reversal of acid-induced acute lung injury by blocking of platelet-neutrophil aggregation. J Clin Invest 2006;116:3211-3219.

42 Ding ZM, Babensee JE, Simon SI, Lu H, Perrard JL, Bullard DC, Dai XY, Bromley SK, Dustin ML, Entman ML, Smith CW, Ballantyne CM: Relative contribution of LFA-1 and Mac-1 to neutrophil adhesion and migration. J Immunol 1999;163:5029-5038.

43 Eppinger MJ, Deeb GM, Bolling SF, Ward PA: Mediators of ischemia-reperfusion injury of rat lung. Am J Pathol 1997;150:17731784.

44 Sakr Y, Dubois MJ, De Backer D, Creteur J, Vincent JL: Persistent microcirculatory alterations are associated with organ failure and death in patients with septic shock. Crit Care Med 2004;32:1825-1831.

45 Trzeciak S, McCoy JV, Phillip DR, Arnold RC, Rizzuto M, Abate NL, Shapiro NI, Parrillo JE, Hollenberg SM: Early increases in microcirculatory perfusion during protocoldirected resuscitation are associated with reduced multi-organ failure at $24 \mathrm{~h}$ in patients with sepsis. Intensive Care Med 2008;34: 2210-2217.

46 De Backer D, Creteur J, Dubois MJ, Sakr Y, Vincent JL: Microvascular alterations in patients with acute severe heart failure and cardiogenic shock. Am Heart J 2004;147:91-99.

47 Klijn E, Den Uil CA, Bakker J, Ince C: The heterogeneity of the microcirculation in critical illness. Clin Chest Med 2008;29:643654.

48 Bauer P, Lush CW, Kvietys PR, Russell JM, Granger DN: Role of endotoxin in the expression of endothelial selectins after cecal ligation and perforation. Am J Physiol Regul Integr Comp Physiol 2000;278:R1140R1147.

49 Lush CW, Cepinskas G, Sibbald WJ, Kvietys PR: Endothelial E- and P-selectin expression in iNOS- deficient mice exposed to polymicrobial sepsis. Am J Physiol Gastrointest Liver Physiol 2001;280:G291-G297.

50 Piper RD, Pitt Hyde ML, Anderson LA, Sibbald WJ, Potter RF: Leukocyte activation and flow behavior in rat skeletal muscle in sepsis. Am J Respir Crit Care Med 1998;157: 129-134. 